\title{
ARTICLE OPEN \\ Cortical inhibitory markers of lifetime suicidal behavior in depressed adolescents
}

\author{
Charles P. Lewis (iD), Paul A. Nakonezny ${ }^{2,3}$, Caren J. Blacker ${ }^{1}$, Jennifer L. Vande Voort ${ }^{1}$, John D. Port $\mathbb{D}^{1,4}$, Gregory A. Worrell ${ }^{5}$, \\ Hang Joon $\mathrm{Jo}^{6}$, Zafiris J. Daskalakis ${ }^{7,8}$ and Paul E. Croarkin (iD)
}

\begin{abstract}
Although suicide is the second-leading cause of death in adolescents and young adults worldwide, little progress has been made in developing reliable biological markers of suicide risk and suicidal behavior. Converging evidence suggests that excitatory and inhibitory cortical processes mediated by the neurotransmitters glutamate and $\gamma$-aminobutyric acid (GABA) are dysregulated in suicidal individuals. This study utilized single- and paired-pulse transcranial magnetic stimulation (TMS) to assess excitatory and inhibitory cortical functioning in healthy control adolescents $(n=20)$, depressed adolescents without any history of suicidal behavior ("Depressed", $n=37$ ), and depressed adolescents with lifetime history of suicidal behavior ("Depressed +SB", $n=17$ ). In a fixed-effects general linear model analysis, with age, sex, and depression severity as covariates, no significant group main effects emerged for resting motor threshold, intracortical facilitation, short-interval intracortical inhibition, or cortical silent period. However, group main effects were significant for long-interval intracortical inhibition (LICI) at interstimulus intervals (ISIs) of 100 ms and $150 \mathrm{~ms}$, but not $200 \mathrm{~ms}$. Depressed+SB adolescents demonstrated impaired LICl compared to healthy control and Depressed adolescents, while healthy control and Depressed participants did not differ in LICl. Multiple linear robust regression revealed significant positive linear relationships between lifetime suicidal behavior severity and impairment in $\mathrm{LICl}$ at $100-\mathrm{ms}$ and $150-\mathrm{ms}$ ISIs. In a post hoc receiver operating characteristic analysis, LICI significantly discriminated Depressed from Depressed + SB youth in $100-\mathrm{ms}$ and $150-\mathrm{ms}$ paradigms. These findings suggest that $\mathrm{GABA}_{B}$ receptor-mediated inhibition is distinctly dysregulated in depressed adolescents with histories of suicidal behavior. Further research is warranted to establish the utility of cortical inhibition in the assessment of suicide risk and as a target for treatment interventions.
\end{abstract}

Neuropsychopharmacology (2018) 43:1822-1831; https://doi.org/10.1038/s41386-018-0040-x

\section{INTRODUCTION}

Suicide is the second most common cause of death among adolescents and young adults in the United States [1] and globally [2], with $17.7 \%$ of U.S. adolescents reporting having seriously considered suicide, $14.6 \%$ having made a suicide plan, and $8.6 \%$ having attempted suicide within the preceding 12 months [3]. Additionally, suicidal ideation and attempts during childhood and adolescence predict later suicidal behavior in adulthood [4]. Notably, rates of suicide attempts among adults have increased in recent years [5]. Despite the immense personal, societal, and healthcare burdens associated with suicidal behavior in young people, assessing suicide risk remains a challenge in clinical practice, frequently complicated by the lack of objective, verifiable data. The predictive value of identified suicide risk factors, however, is limited and has not improved substantially over time, despite decades of research [6]. Furthermore, biological correlates investigated to date are weak predictors of suicidal behavior [7]. There is growing recognition of the need for additional quantifiable neurobiological markers to augment current clinical assessments in order to more reliably identify and monitor those at high risk for suicide $[8,9]$.

Previous research has implicated the hypothalamic-pituitaryadrenal stress response system and serotonergic and noradrenergic synaptic transmission in suicide [8] and suicidal behavior [9]. However, increasing evidence suggests that suicidal individuals also have aberrances in amino acid neurotransmitter systems, including $\gamma$-aminobutyric acid (GABA) and glutamate, respectively the principal inhibitory and excitatory transmitters of the mammalian brain. Data supporting the involvement of GABA and glutamate in the pathophysiology of suicidal behavior come from diverse methodologies, including gene association studies [10], analyses of postmortem brain gene expression [11-14] and receptor binding [15, 16], immunohistochemical studies [17], epigenetic research [18], and cerebrospinal fluid studies [19, 20].

The physiology of cortical GABAergic and glutamatergic systems can be probed noninvasively with single- and pairedpulse transcranial magnetic stimulation (TMS) techniques. Stimulation of the motor cortex while varying the intensity of the magnetic pulse and the interstimulus interval (for paired-pulse

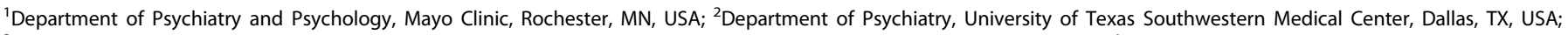

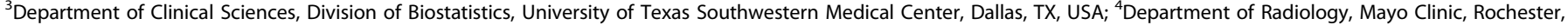

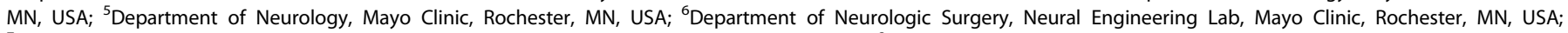

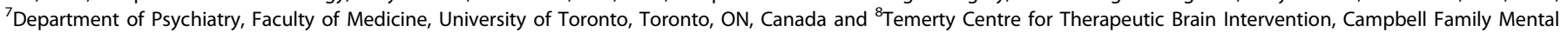
Health Research Institute, Centre for Addiction and Mental Health, University of Toronto, Toronto, ON, Canada Correspondence: Paul E. Croarkin (croarkin.paul@mayo.edu)
}

Received: 24 August 2017 Revised: 5 January 2018 Accepted: 26 February 2018

Published online: 14 March 2018 
paradigms) elicits distinct excitatory and inhibitory effects that can be measured with simultaneous electromyographic (EMG) recording of the contralateral limb. These include inhibitory effects mediated by ionotropic $\mathrm{GABA}_{\mathrm{A}}$ and metabotropic $\mathrm{GABA}_{\mathrm{B}}$ receptors, such as the cortical silent period (CSP), short-interval intracortical inhibition (SICI), and long-interval intracortical inhibition (LICl), as well as indices of glutamate receptor-mediated excitatory functioning, such as the resting motor threshold (RMT) and intracortical facilitation (ICF). Mechanisms of these excitatory and inhibitory TMS measures have been elucidated through extensive animal and human experiments (for a review, see ref. [21]).

Single- and paired-pulse TMS have been used to investigate cortical excitability and inhibition in a variety of psychiatric conditions, including depression in adult populations [22, 23]. Meta-analysis of adult studies [24] found shorter CSP and reduced $\mathrm{SICl}$ in depressed individuals compared to healthy controls. However, adolescents with major depressive disorder appear to have a different pattern of altered cortical excitability [25]. Although suicidal ideation and behavior are common symptoms among adolescents with depression, it remains undetermined whether suicidality confers a neurobiological signature distinct from that of depression alone. To our knowledge, no prior research has utilized TMS to investigate cortical excitability and inhibition as an index of suicidality. Thus, the primary aim of this study was to examine single- and paired-pulse TMS measures of cortical excitability (RMT, ICF) and inhibition (CSP, SICl, LICI) in depressed adolescents with and without histories of suicidal behavior and in a healthy control comparator group. We hypothesized that adolescents with histories of suicidal behavior would have impaired inhibition (CSP, SICl, $\mathrm{LICl}$ ) compared to healthy control and depressed adolescents without histories of suicidal behavior. As a secondary aim, we examined the relationship between severity of lifetime suicidal behavior and TMS measures of cortical inhibition (CSP, SICl, LICl) and excitability (RMT, ICF). Additionally, as an exploratory analysis, we examined the ability of a cortical inhibitory measure (LICI) to discriminate depressed youth without histories of suicidal behavior from those with lifetime suicidal behavior.

\section{MATERIALS AND METHODS}

The current study is based on a pooled sample from three extant individual studies that utilized identical clinical assessments and TMS methods. In this cross-sectional study, a clinical assessment preceded TMS cortical excitability and inhibition measures, which were obtained during a single session. The study was approved by the institutional review boards of Mayo Clinic (Rochester, MN, USA) and the University of Texas Southwestern Medical Center (Dallas, TX, USA).

\section{Participants}

Participants consisted of treatment-seeking depressed adolescents recruited from clinical practice and healthy adolescents recruited through community advertising. Prior to any study assessments or procedures, all minor participants provided written assent, and a parent or guardian granted written informed consent; all participants aged $\geq 18$ years provided written informed consent.

Eligible participants were English-speaking adolescents between the ages of 12 and 21 years; minor participants also were required to have a parent or guardian fluent in English. Participants underwent a structured diagnostic interview, the Schedule for Affective Disorders and Schizophrenia for SchoolAge Children (K-SADS-PL; [26]). Participants eligible for the Healthy Control group $(n=20)$ did not meet criteria for any psychiatric diagnosis (past or present), had no family history of psychiatric diagnosis in first-degree relatives, and had no history of psychotropic medication use, psychotherapy, or suicidal behavior. Eligibility for the depressed groups required the diagnosis of a depressive disorder on the K-SADS-PL. Depression severity was assessed on the clinician-rated Children's Depression Rating Scale, Revised (CDRS-R; [27]); in the interest of broadbased external validity, and considering that youth with a range of depressive symptoms may engage in suicidal behavior, no minimal score was required. Depressed participants' recent and lifetime histories of suicidal ideation and behavior were assessed on clinical interview using the Columbia-Suicide Severity Rating Scale (C-SSRS; [28]). Participants with either no history of suicidal behavior or a history of isolated non-suicidal self-injurious behavior (i.e., self-injury with clearly non-suicidal intent and no history of suicidal preparatory behavior, aborted or interrupted attempt, or actual attempt) were classified in the depressed without lifetime history of suicidal behavior ("Depressed") group $(n=37)$. Participants with any lifetime history of preparatory behavior, aborted or interrupted attempt, or actual suicide attempt were classified in the depressed with lifetime history of suicidal behavior ("Depressed+SB") group $(n=17)$. Classification was also confirmed based on review of clinical records and consultation with the treating psychiatrist. All structured interviews and clinical assessments were performed by a boardcertified child and adolescent psychiatrist (PEC).

Exclusion criteria included increased risk of seizure (e.g., personal history of epilepsy, febrile or unprovoked seizures, intracranial tumor, or intracranial surgical procedure; family history of epilepsy) or other contraindication to TMS (implanted ferromagnetic device or metallic fragments, not including orthodontic hardware) as assessed on the TMS Adult Safety Screen [29]. Additionally, adolescents were excluded if they had primary psychiatric diagnoses other than depressive disorders, were pregnant or at risk of pregnancy (for post-menarchal female participants), had unstable medical conditions, or were evaluated by a study psychiatrist to be at imminent risk of medically serious self-injury or suicide at the time of participation.

Procedures and measures

All study participants underwent single- and paired-pulse TMS of the left primary motor cortex to assess cortical excitability and inhibition. During stimulation, participants remained seated and wore earplugs for noise safety and comfort. Electromyographic (EMG) electrodes affixed to the surface of the skin overlying the contralateral (right) abductor pollicis brevis (APB) muscle recorded motor evoked potentials (MEPs) throughout the TMS session. Procedures for determining coil position and excitatory and inhibitory measures have been published previously [30]. Participants were permitted to continue their prescribed psychotropic medications during the study, although stimulants were held on the day of TMS testing.

Magnetic pulses were generated by two Magstim 200 stimulators connected by a BiStim module (Magstim Co. Ltd., Whitland, Wales, UK) and delivered with a figure-of-eight electromagnetic coil (70 mm diameter, each loop) held tangentially against the scalp. The area of motor cortex responsible for APB movement was localized by stimulating with single pulses at a constant intensity while shifting the coil in $1-\mathrm{cm}$ increments until maximal muscle movement was observed visually. After the optimal APB position was localized, coil position was held constant while the stimulus intensity was increased gradually. The stimulus intensity at which MEP amplitude observed on EMG was at least $50 \mu \mathrm{V}$ in 5 out of 10 trials was defined as the resting motor threshold (RMT) [31].

The CSP was determined by single-pulse stimulation of the left primary motor cortex at $140 \%$ of the RMT while the participant voluntarily contracted the right APB at $20 \%$ of maximum contraction (determined by hand-held dynamometer). The duration of interruption in voluntary motor activity (from the 
a

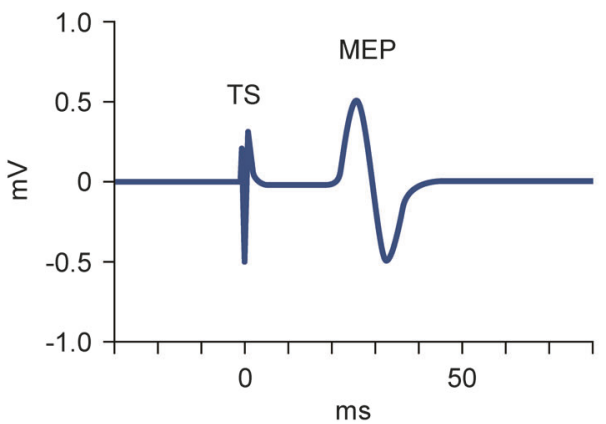

b

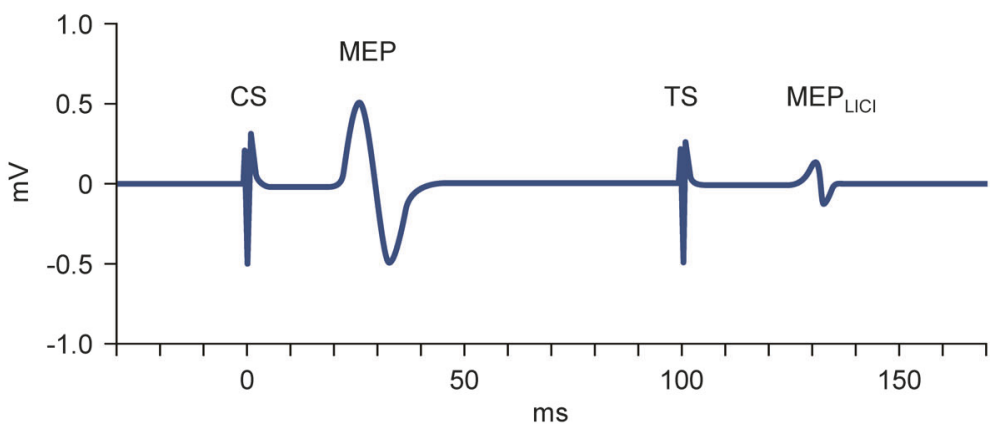

Fig. 1 Schematic illustration of typical electromyographic recordings of single- and paired-pulse transcranial magnetic stimulation of the primary motor cortex as measured in electrodes overlying the abductor pollicis brevis (APB). a When a single magnetic test stimulus (TS) at an intensity above the resting motor threshold is applied to the area of the primary motor cortex corresponding to the APB $($ at time $=0$ ), a motor evoked potential (MEP) is recorded in the contralateral APB electrode shortly afterward. $\mathbf{b}$ In the long-interval intracortical inhibition (LICI) paired-pulse paradigm, a suprathreshold (i.e., above the resting motor threshold) conditioning stimulus (CS) is delivered to the primary motor cortex (at time $=0$ ), which results in an unconditioned MEP. After an interstimulus interval of 100-200 ms (100 ms shown), a second, identical test stimulus (TS) is administered. The resulting conditioned MEP (MEP LICI $_{\text {) }}$ is diminished in amplitude. This inhibition is mediated predominantly by cortical $\mathrm{GABA}_{\mathrm{B}}$ receptors.

beginning of the TMS pulse to the resumption of motor activity on EMG) was measured in 10 trials and averaged.

For $\mathrm{SICl}, \mathrm{LICl}$, and ICF measures, paired conditioning and test stimuli were delivered while the APB was at rest. In the $\mathrm{SICl}$ and ICF paradigms, a subthreshold ( $80 \%$ RMT) conditioning stimulus preceded the test stimulus, whose intensity was calibrated to generate peak-to-peak MEP amplitudes of $1.0 \mathrm{mV}$. A schematic representation of an EMG recording of an MEP resulting from a single TMS test stimulus is illustrated in Fig. 1a. For $\mathrm{SICl}$, interstimulus intervals (ISIs) were $2 \mathrm{~ms}$ and $4 \mathrm{~ms}$, while for the ICF paradigm, ISIs were $10 \mathrm{~ms}, 15 \mathrm{~ms}$, and $20 \mathrm{~ms}$. By contrast, the $\mathrm{LICl}$ paradigm (Fig. 1b) involved suprathreshold conditioning and test stimuli (both calibrated to result in 1.0-mV peak-to-peak MEP amplitudes) and ISIs of $100 \mathrm{~ms}, 150 \mathrm{~ms}$, and $200 \mathrm{~ms}$. Amplitudes of the conditioned MEPs (the MEPs resulting from the test stimuli) were recorded on EMG (12 trials at each ISI for SICI and ICF; 10 trials at each ISI for $\mathrm{LICl}$ ) and averaged. For all paired-pulse measures, amplitudes of conditioned MEPs are expressed as ratios to the mean unconditioned MEP amplitude. Trials of all three paired-pulse paradigms were performed concurrently in a randomized and counterbalanced order.

\section{Outcome variables}

The primary outcomes were TMS measures of cortical inhibition (CSP duration; $\mathrm{SICl}$ and $\mathrm{LICl}$ conditioned/unconditioned MEP amplitude ratios) and excitability (RMT; ICF conditioned/unconditioned MEP amplitude ratios).

\section{Independent variables and covariates}

The primary independent variable was group membership (Healthy Control vs. Depressed vs. Depressed+SB). Participants' highest level of lifetime suicidal behavior severity, as assessed on the C-SSRS at study entry, was a predictor (independent) variable in the regression models. An ordinal scale of suicidal behavior was operationally defined as: $0=$ none; $1=$ non-suicidal self-injury; 2 $=$ planning/preparation for a suicide attempt; $3=$ interrupted or aborted attempt; $4=$ suicide attempt. Sex, age in years, and depressive symptom severity at study entry were included as covariates in the models. Depression severity was assessed using the CDRS-R total score.

Statistical analysis

Demographic and clinical characteristics of the participants were described using the sample mean and standard deviation for continuous variables and the frequency and percentage for categorical variables. One-way analysis of variance (for continuous variables) and Fisher's exact test (for categorical variables) were used to test for differences among the three groups (Healthy Control vs. Depressed vs. Depressed+SB) on demographic characteristics and between the two depressed groups (Depressed vs. Depressed+SB) on clinical characteristics.

For the primary aim, a fixed-effects general linear model (GLM) was used to examine the group main effect (Healthy Control vs. Depressed vs. Depressed+SB) on each of the TMS outcome measures of cortical inhibition (CSP, SICl, LICl) and excitability (RMT, ICF). Group least squares means of the TMS outcome measure estimates were compared for a total of three post hoc pair-wise contrasts, with $p$-values adjusted for multiple comparisons using the Tukey-Kramer method. A weight statement was included in the model to account for (and down-weight) any potential outliers (see supplementary materials and methods for details). For the secondary aim, multiple linear robust regression (with MM estimation) and the Spearman partial correlation coefficient $\left(r_{\mathrm{s}}\right)$ were used to examine the relationship between severity of lifetime suicidal behavior and each TMS outcome measure, while adjusting for age, sex, and CDRS-R total score. Additional technical details regarding the GLM and robust regression analyses are available in supplementary materials and methods.

Finally, as a post hoc sensitivity analysis, a receiver operating characteristic (ROC) analysis alongside the area under the curve (AUC) was conducted to determine the optimal conditioned/ unconditioned MEP amplitude ratio cutpoints for each of the $\mathrm{LICl}$ paradigms (100-ms, 150-ms, and 200-ms ISIs), based on the Youden index, in discriminating Depressed vs. Depressed+SB status. The AUC associated with each optimal cutpoint was tested against a nominal area of 0.50 using the $Z$ statistic. The $95 \%$ binomial exact confidence intervals (Cls) were calculated for the AUC. Sensitivity, specificity, positive predictive value (PPV), and negative predictive value (NPV) were reported for each of the optimal cutpoints.

Statistical analyses were carried out using the SAS software, version 9.4 (SAS Institute, Inc., Cary, NC, USA). The procedures of PROC GLIMMIX and PROC ROBUSTREG in the SAS software were used to conduct the analyses for the primary and secondary aims. The level of significance was set at $a=0.05$ (two-tailed), and to address multiple testing (where applicable), $p$-values were adjusted using the False Discovery Rate (FDR) procedure [32]. 


\begin{tabular}{|c|c|c|c|c|c|}
\hline Participant characteristic & $\begin{array}{l}\text { Overall sample } \\
\quad(n=74)\end{array}$ & $\begin{array}{l}\text { Healthy Control } \\
\quad(n=20)\end{array}$ & $\begin{array}{l}\text { Depressed }^{\mathrm{a}} \\
(n=37)\end{array}$ & $\begin{array}{l}\text { Depressed }+\mathrm{SB}^{\mathrm{b}} \\
\quad(n=17)\end{array}$ & $p$-value $\left(p_{\mathrm{FDR}}\right)$ \\
\hline Age in years, $M \pm S D$ & $15.33 \pm 1.89$ & $14.20 \pm 1.76$ & $15.70 \pm 1.88$ & $15.88 \pm 1.57$ & $0.005(0.015)$ \\
\hline Sex, \% (n) & & & & & $0.319(0.362)$ \\
\hline Female & $59.46 \%(44)$ & $45.00 \%(9)$ & $64.86 \%(24)$ & $64.71 \%(11)$ & \\
\hline Right-handed, \% ( $n$ ) & $93.24 \%(69)$ & $90.00 \%(18)$ & $100 \%(37)$ & $82.35 \%(14)$ & $0.023(0.051)$ \\
\hline Race/ethnicity, \% (n) & & & & & $0.001(0.004)$ \\
\hline African-American & $16.22 \%(12)$ & $45.00 \%(9)$ & $5.41 \%(2)$ & $5.88 \%(1)$ & \\
\hline Asian-American & $2.70 \%(2)$ & $0.00 \%(0)$ & $5.41 \%(2)$ & $0.00 \%(0)$ & \\
\hline Caucasian, Non-Hispanic & $67.56 \%(50)$ & $40.00 \%(8)$ & $78.37 \%(29)$ & $76.47 \%(13)$ & \\
\hline CDRS-R total score, $\mathrm{M} \pm \mathrm{SD}$ & $36.59 \pm 15.78$ & $19.65 \pm 1.69$ & $41.48 \pm 13.03$ & $45.88 \pm 15.64$ & $0.285(0.362)$ \\
\hline Length of illness (years), $M \pm S D$ & $2.27 \pm 1.96$ & $\mathrm{~N} / \mathrm{A}$ & $2.08 \pm 1.93$ & $2.67 \pm 2.05$ & $0.313(0.362)$ \\
\hline $\begin{array}{l}\text { Currently prescribed psychotropic } \\
\text { medications, } \%(n)\end{array}$ & $43.24 \%(32)$ & $0.00 \%(0)$ & $54.05 \%(20)$ & $70.59 \%(12)$ & $0.372(0.372)$ \\
\hline Familial psychiatric history, $\%(n)$ & $69.86 \%(51)$ & $0.00 \%(0)$ & $94.44 \%(34)^{c}$ & $100 \%(17)$ & $0.322(0.362)$ \\
\hline $\begin{array}{l}\text { Maximal lifetime history of suicidal } \\
\text { behavior, } \%(n)\end{array}$ & & & & & $0.0001(0.001)$ \\
\hline None & $66.22 \%(49)$ & $100 \%(20)$ & $78.38 \%(29)$ & $0.00 \%(0)$ & \\
\hline Non-suicidal self-injury & $10.81 \%(8)$ & $0.00 \%(0)$ & $21.62 \%(8)$ & $0.00 \%(0)$ & \\
\hline $\begin{array}{l}\text { Planning/preparation for a suicide } \\
\text { attempt }\end{array}$ & $2.70 \%(2)$ & $0.00 \%(0)$ & $0.00 \%(0)$ & $11.76 \%(2)$ & \\
\hline
\end{tabular}

\section{RESULTS}

Participant characteristics

Of the entire sample of 74 adolescent participants, $59.46 \%$ were female and $67.56 \%$ were non-Hispanic Caucasian. The mean age was $15.33 \pm 1.89$ years (range $=12-20$ years). Mean CDRS-R total score was $36.59 \pm 15.78$. Of the 74 youths, $66.22 \%$ reported no lifetime history of suicidal behavior, but $10.81 \%$ reported nonsuicidal self-injury. Demographic and clinical characteristics of the overall sample and each group are shown in Table 1, with comparisons of all three groups on demographic characteristics and of the two depressed groups on clinical characteristics. A list of concurrent psychotropic medications taken by participants in the Depressed and Depressed+SB groups at the time of TMS testing is provided in Supplementary Table S1.

Cortical excitability

The GLM analysis revealed no significant group main effect for $\operatorname{RMT}\left(F_{2,68}=0.16, p=0.8484, p_{\mathrm{FDR}}=0.8484\right)$. For the ICF paradigm, the GLM analysis showed no significant group main effects for conditioned/unconditioned MEP amplitude ratio at the 10-ms ISI $\left(F_{2,67}=1.04, p=0.3601, p_{\mathrm{FDR}}=0.4801\right), 15-\mathrm{ms}$ ISI $\left(F_{2,67}=1.18, p=\right.$ $\left.0.3127, p_{\mathrm{FDR}}=0.4801\right)$, or 20-ms ISI $\left(F_{2,68}=0.0869, p=0.0945\right.$, $p_{\text {FDR }}=0.3780$ ). Least squares mean and standard error values for TMS measures of cortical excitability are reported in Table 2.

The multiple linear robust regression (Table 3 ), while adjusting for age, sex, and CDRS-R total score, revealed a non-significant negative linear relationship between lifetime suicidal behavior severity and $\operatorname{RMT}(\hat{b}=-0.5160, p=0.6333)$, as well as nonsignificant negative linear relationships between lifetime suicidal behavior severity and conditioned/unconditioned MEP amplitude ratio in the $10-\mathrm{ms}(\hat{b}=-0.0655, p=0.1812), 15-\mathrm{ms}(\hat{b}=-0.0410, p$ $=0.3986)$, and $20-\mathrm{ms}(\hat{b}=-0.0483, p=0.4059)$ ICF paradigms.

Cortical inhibition

The GLM analysis revealed no significant group main effect for CSP duration $\left(F_{2,59}=2.18, p=0.1216, p_{\mathrm{FDR}}=0.2432\right)$ or for conditioned/unconditioned MEP amplitude ratio in the $\mathrm{SICl}$ paradigm at the 2-ms ISI $\left(F_{2,68}=0.50, p=0.6061, p_{\mathrm{FDR}}=0.6061\right)$ or 4-ms ISI $\left(F_{2,67}=0.67, p=0.5158, p_{\mathrm{FDR}}=0.6061\right)$. However, significant group main effects did emerge for conditioned/ unconditioned MEP amplitude ratio in the $\mathrm{LICl}$ paradigm at 100 $\mathrm{ms}\left(F_{2,55}=10.08, p=0.0002, p_{\mathrm{FDR}}=0.0012\right)$ and $150 \mathrm{~ms}\left(F_{2,54}=\right.$ 
Table 2. Cortical excitability and inhibition results by group

\begin{tabular}{|c|c|c|c|c|}
\hline TMS measure & \multicolumn{4}{|l|}{ Least squares mean (SE) } \\
\hline \multicolumn{5}{|l|}{ Cortical excitability } \\
\hline \multicolumn{5}{|l|}{$\mathrm{ICF}^{\mathrm{e}}$} \\
\hline $\mathrm{ISI}=10 \mathrm{~ms}$ & $1.476(0.128)$ & $1.580(0.086)$ & $1.398(0.102)$ & $0.3601(0.4801)$ \\
\hline \multicolumn{5}{|l|}{ Cortical inhibition } \\
\hline $\operatorname{CSP}^{f}$ & $0.184(0.011)$ & $0.166(0.005)$ & $0.150(0.010)$ & $0.1216(0.2432)$ \\
\hline \multicolumn{5}{|l|}{$\mathrm{SICl}^{\mathrm{e}}$} \\
\hline $\mathrm{ISI}=2 \mathrm{~ms}$ & $0.505(0.069)$ & $0.430(0.043)$ & $0.406(0.066)$ & $0.6061(0.6061)$ \\
\hline $\mathrm{ISI}=4 \mathrm{~ms}$ & $0.751(0.091)$ & $0.642(0.052)$ & $0.707(0.074)$ & $0.5158(0.6061)$ \\
\hline$I S I=200 \mathrm{~ms}$ & $0.975(0.143)$ & $0.795(0.084)$ & $0.713(0.147)$ & $0.5147(0.6061)$ \\
\hline \multicolumn{5}{|c|}{$\begin{array}{l}\text { Note: } p_{\mathrm{FDR}} \text { calculated separately by cortical excitability vs. inhibition. Least squares means are adjusted for age, sex, and CDRS-R total score. } \\
R M T \text { resting motor threshold, ICF intracortical facilitation, ISI interstimulus interval, CSP cortical silent period, SICI short-interval intracortical inhibiti } \\
\text { interval intracortical inhibition, SE robust/empirical standard error estimate, FDR False Discovery Rate described by Benjamini and Hochberg [3 } \\
\text { a Depressive disorder without lifetime history of suicidal behavior (SB) } \\
{ }^{\mathrm{b}} \text { Depressive disorder with lifetime history of SB } \\
{ }^{c} \text { Omnibus test of the group main effect (Healthy Controls vs. Depressed vs. Depressed+SB) on each of the TMS outcome measures } \\
{ }^{\mathrm{d}} \mathrm{RMT} \text { is expressed as the percentage of maximal device output } \\
{ }^{\mathrm{E}} \mathrm{ICF} \text {, SICI, and LICI conditioned motor evoked potential (MEP) amplitudes are expressed as ratios to the mean unconditioned MEP amplitudes } \\
{ }^{\mathrm{f}} \mathrm{CSP} \text { duration is expressed in seconds }\end{array}$} \\
\hline
\end{tabular}

7.51, $\left.p=0.0013, p_{\mathrm{FDR}}=0.0039\right)$, but not at the 200-ms ISI $\left(F_{2,56}=\right.$ $\left.0.67, p=0.5147, p_{\mathrm{FDR}}=0.6061\right)$. In post hoc group comparisons (pair-wise contrasts), the pattern of the least squares means showed that the Depressed+SB group demonstrated significantly higher mean conditioned/unconditioned MEP amplitude ratio than the Healthy Control $\left(t_{55}=4.38, p_{\text {adjusted }}=0.0002\right)$ and Depressed $\left(t_{55}=3.29, p_{\text {adjusted }}=0.0049\right)$ groups in the $100-\mathrm{ms}$ $\mathrm{LICl}$ paradigm, while the Depressed and Healthy Control groups did not differ $\left(t_{55}=1.52, p_{\text {adjusted }}=0.2913\right)$ (Fig. 2). In the $150-\mathrm{ms}$ $\mathrm{LICl}$ paradigm, the pattern of the least squares means showed that the Depressed+SB group demonstrated significantly higher mean conditioned/unconditioned MEP amplitude ratio than the Healthy Control $\left(t_{54}=3.87, p_{\text {adjusted }}=0.0009\right)$ and Depressed $\left(t_{54}=2.49\right.$, $\left.p_{\text {adjusted }}=0.0418\right)$ groups, while the Depressed and Healthy Control groups did not differ $\left(t_{54}=2.17, p_{\text {adjusted }}=0.0860\right)$ (Fig. 2). Least squares mean and standard error values for TMS measures of cortical inhibition are reported in Table 2. Note that higher conditioned/unconditioned MEP amplitude ratio values in the $\mathrm{LICl}$ paradigms reflect impairment in cortical inhibition and $\mathrm{GABA}_{\mathrm{B}^{-}}$ mediated inhibitory neurotransmission.

The multiple linear robust regression, while adjusting for age, sex, and CDRS-R total score, revealed a non-significant negative linear relationship between lifetime suicidal behavior severity and CSP $(\hat{b}=-0.0058, p=0.0723)$ and between lifetime suicidal behavior severity and conditioned/unconditioned MEP amplitude ratio in the $2-\mathrm{ms}(\hat{b}=-0.0213, p=0.4268)$ and $4-\mathrm{ms}(\hat{b}=-0.0069$, $p=0.8439) \mathrm{SICl}$ paradigms. However, the robust regression did reveal significant positive linear relationships between severity of lifetime suicidal behavior and conditioned/unconditioned MEP amplitude ratio in the LICI paradigm at the $100-\mathrm{ms}$ ISI $(\hat{b}=0.0792$, $\left.p=0.0041, p_{\mathrm{FDR}}=0.0123\right)$ and $150-\mathrm{ms} \mathrm{ISI}(\hat{b}=0.0953, p=0.0017$, $\left.p_{\mathrm{FDR}}=0.0102\right)$, but not at the $200-\mathrm{ms}$ ISI $(\hat{b}=-0.0266, p=0.6138)$. Robust regression results are reported in Table 3 . We also present scatterplots of the conditioned/unconditioned MEP amplitude ratio values against lifetime suicidal behavior severity, with a fitted robust regression line and $95 \%$ confidence limits, for the $100-\mathrm{ms}$ (Fig. 3a) and 150-ms (Fig. 3b) $\mathrm{LICl}$ paradigms.

The ROC analysis determined that the $100-\mathrm{ms} \mathrm{LICl}$ paradigm, with a conditioned/unconditioned MEP amplitude ratio cutoff $\leq 0.2108$ (based on the Youden index), best discriminated Depressed youth from Depressed $+\mathrm{SB}$ youth $(\mathrm{AUC}=0.799, \mathrm{SE}=$ $0.068,95 \%$ binomial exact $\mathrm{Cl}$ : $0.651-0.905, Z=4.34, p=0.0001$, $\left.p_{\mathrm{FDR}}=0.0003\right)$, with $54.84 \%$ sensitivity, $92.31 \%$ specificity, a PPV of $94.40 \%$, and an NPV of $46.20 \%$. In the $150-\mathrm{ms}$ LICl paradigm, the ROC analysis determined that a conditioned/unconditioned MEP amplitude ratio cutoff $\leq 0.7003$ (based on the Youden index) best discriminated Depressed youth from Depressed + SB youth (AUC $=0.769, \mathrm{SE}=0.081,95 \%$ binomial exact Cl: 0.618-0.883, $Z=3.32$, $p=0.0009, p_{\mathrm{FDR}}=0.0014$ ), with $93.55 \%$ sensitivity, $53.85 \%$ specificity, a PPV of $82.90 \%$, and an NPV of $77.80 \%$. The ROC analysis, however, determined that the 200-ms LICl paradigm, with a conditioned/unconditioned MEP amplitude ratio cutoff $\leq 0.9246$ (based on the Youden index), did not significantly discriminate Depressed youth from Depressed + SB youth $(A U C=0.511, \mathrm{SE}=$ 0.097, 95\% binomial exact Cl: $0.356-0.665, Z=0.11, p=0.9086$, $p_{\text {FDR }}=0.9086,67.74 \%$ sensitivity, $46.15 \%$ specificity, a PPV of $75.00 \%$, and an NPV of $37.50 \%$ ). The ROC curves for the $\mathrm{LICl}$ paradigms (100-ms, 150-ms, and 200-ms ISIs) are shown in Fig. 4a-c.

\section{DISCUSSION}

Long-interval intracortical inhibition [33-37] is thought to reflect cortical inhibitory processes mediated by the metabotropic $\mathrm{GABA}_{B}$ receptor. This is based on the chronology of the $\mathrm{LICl}$ effect, whose range of ISIs corresponds to the timing of inhibitory postsynaptic potentials mediated by the $\mathrm{GABA}_{\mathrm{B}}$ receptor in motor cortical neurons $[36,38]$, as well as the higher intensity of the conditioning 


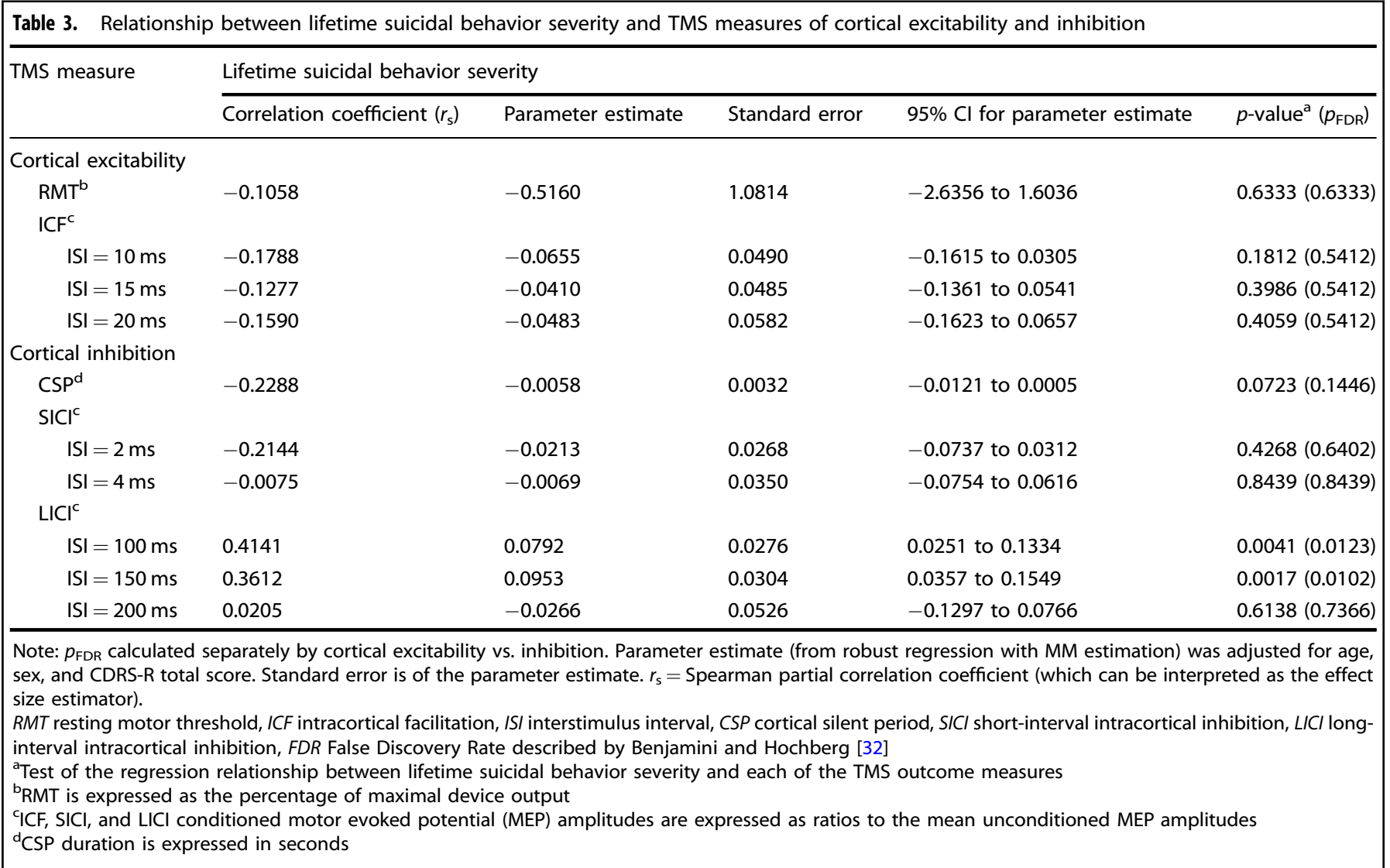

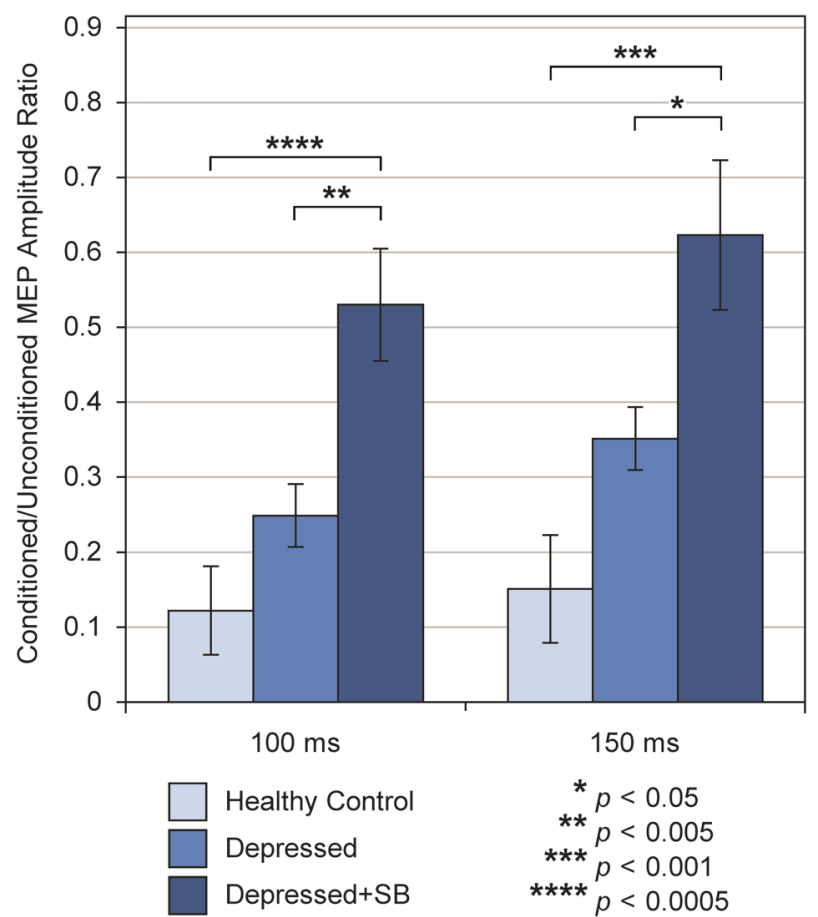

Fig. 2 Long-interval intracortical inhibition (LICI) by group. Mean conditioned/unconditioned MEP amplitude ratio values at interstimulus intervals (ISIs) of $100 \mathrm{~ms}$ and $150 \mathrm{~ms}$ are displayed by group. Error bars represent robust/empirical standard error estimates. Note that higher conditioned/unconditioned MEP amplitude ratio values in the $\mathrm{LICl}$ paradigm reflect impairment in cortical inhibition and $\mathrm{GABA}_{\mathrm{B}}$-mediated inhibitory neurotransmission. stimulus necessary for $\mathrm{LICl}$ (compared to $\mathrm{SICl}$ ), which mirrors the higher thresholds required for activation of $G A B A_{B}$ receptors relative to $G_{A B A}$ activation thresholds [36]. Additionally, $\mathrm{LICl}$ is potentiated by the $G_{A B A_{B}}$ receptor agonist baclofen [39] and agents that increase synaptic GABA, such as tiagabine [38] and vigabatrin [40], while benzodiazepines (positive allosteric modulators at the $\mathrm{GABA}_{A}$ receptor) do not impact $\mathrm{LICI}[41,42]$.

In our study, there was a significant group effect for LICI at ISIs of $100 \mathrm{~ms}$ and $150 \mathrm{~ms}$, with adolescents in the Depressed+SB group exhibiting significantly higher conditioned/unconditioned MEP amplitude ratios (i.e., impaired $\mathrm{LICl}$ ) than adolescents in either the Healthy Control or the Depressed groups in post hoc comparisons. Although the Depressed group's mean conditioned/unconditioned MEP amplitude ratio values were intermediate between those of the Healthy Control and Depressed+SB groups, the differences between the Depressed and Healthy Control groups were not significant. This suggests that $G_{A B A}-$ mediated inhibitory processes are more disrupted in depressed adolescents with suicidal behavior than in those with depression alone. While the Depressed+SB group had slightly higher mean depression severity than the Depressed group (CDRS-R total scores of 45.88 vs. 41.48), this does not represent a clinically meaningful difference, and furthermore, our analysis included depression severity as a covariate. Thus, the observed differences in $\mathrm{LICl}$ between Depressed and Depressed+SB adolescents are unlikely to represent the effect of more severe depressive symptoms in the adolescents with histories of suicidal behavior. Impairment in LICI may instead be related uniquely to history of suicidal behavior in this depressed adolescent sample. Additionally, in the multiple linear robust regression analysis for the 100$\mathrm{ms}$ and $150-\mathrm{ms} \mathrm{LICl}$ paradigms, there were significant positive linear relationships between the ordinal lifetime suicidal behavior severity variable and the conditioned/unconditioned MEP amplitude ratios. This raises the question of whether increasingly severe 
a

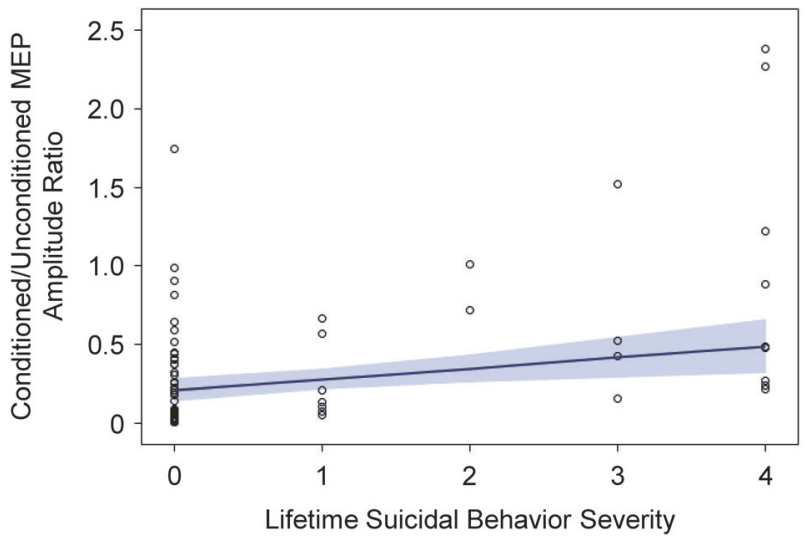

b

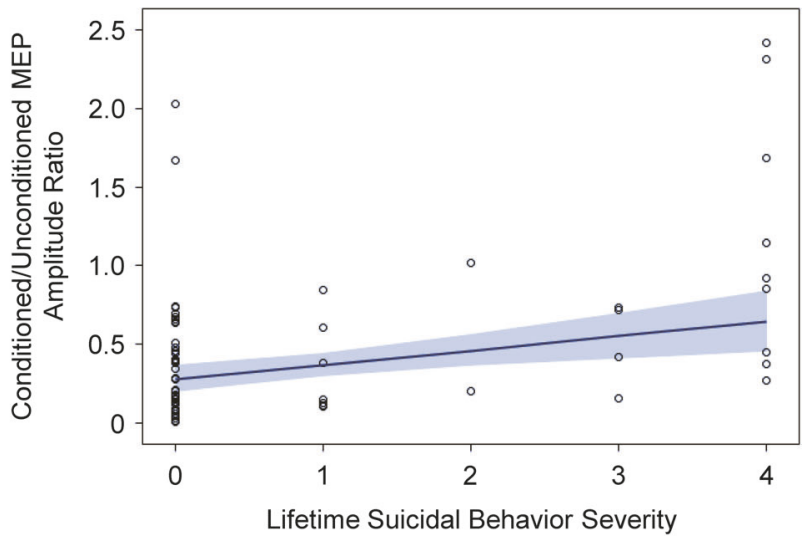

Fig. 3 Relationship between severity of lifetime suicidal behavior and LICI. Scatterplots of the conditioned/unconditioned MEP amplitude ratio values in the LICI paradigms (a 100-ms ISI; b 150-ms ISI) are plotted against lifetime suicidal behavior severity, with fitted robust regression lines and $95 \%$ confidence limits, in the overall sample of adolescent participants.

suicidal behavior corresponds to greater deficits in cortical inhibition. Furthermore, the ROC analysis suggested that $\mathrm{LICl}$ could discriminate the presence and absence of a lifetime history of suicidal behavior among depressed youth, with the 150-ms paradigm exhibiting superior sensitivity and the 100 -ms paradigm demonstrating superior specificity. The absence of group differences in $\mathrm{LICl}$ at the $200-\mathrm{ms} \mathrm{ISI}$, of a significant relationship between suicidal behavior severity and $\mathrm{LICl}$ in the 200-ms regression, and of better-than-chance discriminating ability for 200-ms LICl in the ROC analysis may be related to late disinhibition effects [37, 43, 44] that overlap with and persist beyond $\mathrm{LICl}$, representing a gradual transition from net inhibition to net facilitation that occurs in cortical networks following magnetic stimulation.

The Depressed+SB group exhibited the shortest mean CSP duration, while Healthy Controls had the longest mean CSP; however, the group effect failed to reach the threshold for significance. Like $\mathrm{LICl}$, the CSP is posited to have $\mathrm{GABA}_{\mathrm{B}}$-mediated mechanisms $[36,45]$, but the two effects may involve distinct populations of cortical neurons [46] or be modulated by different cortico-cortical inputs [47]. Additionally, other work has demonstrated the effects of $G_{A B A}$ receptors on the CSP under certain conditions [48]. Notably, $\mathrm{SICl}$ (a putative index of $\mathrm{GABA}_{A}$-mediated inhibition) did not differ between groups in our study.

Our findings suggest that cortical inhibition mediated by the $G A B A_{B}$ receptor, rather than the $G A B A_{A}$ receptor, may be altered in adolescents with suicidal behavior. Interestingly, this stands somewhat in contrast to the adult literature, which is notable for a number of studies that implicate the $G A B A_{A}$ receptor in suicide and a paucity of evidence for $G A B A_{B}$ involvement [11-14, 18]. One potential explanation is that the composition and function of cortical GABAergic inhibitory systems is dynamic throughout neurodevelopment. In early life, $\mathrm{GABA}_{\mathrm{A}}$ receptor activation results in depolarization, later transitioning to its mature inhibitory function $[49,50]$. This may be related in part to differential expression of the various $\mathrm{GABA}_{\mathrm{A}}$ receptor subunits, which shifts substantially from infancy through adulthood [51, 52], as well as age-related changes in the expression of cotransporters affecting the receptor's function $[50,52] . G A B A_{B}$ receptor functions also undergo developmental changes; whereas $G_{A B A}$-mediated presynaptic inhibition is present at birth, postsynaptic inhibition is absent in early development $[49,53]$. Additionally, GABA receptor density continues to change into early adulthood, although at different rates in different brain regions, with the cortex maturing at a later age than subcortical structures [54]. These shifts in GABA receptor function and distribution, interacting with the simultaneous development of glutamatergic systems [49, 52], results in a highly dynamic cortical excitatory-inhibitory balance during childhood and adolescence, with mature GABAergic inhibition arising gradually and relatively late in brain development $[50,52]$. Another important caveat in comparing our findings to previous adult research is that the majority of adult studies involved the use of gene- or receptor-specific methodologies to examine postmortem brain tissue of suicide victims, whereas the TMS measures utilized in our study measure excitatory and inhibitory physiologic functions in vivo.

Cortical inhibitory deficits in suicidal individuals may have important implications for the development of treatments to reduce suicide risk. Sun et al. [55] examined TMSelectroencephalographic measures of cortical inhibition ( $\mathrm{LICl}$ and $\mathrm{N} 100$ ) in the left dorsolateral prefrontal cortex (L-DLPFC) and motor cortex in adults undergoing magnetic seizure therapy (MST) for treatment-resistant depression. The combination of $\mathrm{LICl}$ and N100 in the L-DLPFC predicted remission of suicidal ideation with $89 \%$ accuracy, $90 \%$ sensitivity, and $89 \%$ specificity, with better frontal inhibitory functioning at baseline corresponding to greater likelihood of remission of suicidal ideation with MST [55]. The authors postulated that integrity of inhibitory interneuronal circuits in the frontal cortex mediates the therapeutic response to MST. In addition to serving as a potential predictor of response, cortical inhibition may itself be a target for intervention in suicidal patients. Neuromodulatory techniques, including repetitive TMS (rTMS), are thought to exert their effects through GABAergic mechanisms. Cortical inhibition improves after high-frequency rTMS [56], particularly in individuals with reduced inhibition prior to stimulation [57]. If cortical inhibitory processes are indeed central to the pathophysiology of suicidal behavior, therapeutic interventions that modulate GABAergic networks and improve inhibitory functioning may have great value in future treatment of suicidal individuals.

The current study has some notable limitations. First, the overall sample, while comparable to or larger than those in previous TMS neurophysiology studies, was modest in size, particularly the Depressed+SB group. Future studies, especially those seeking to establish the prognostic utility of cortical inhibition in assessing suicide risk, will require larger numbers of young participants with suicidal behavior. Second, the three groups differed in age ( $p=$ $\left.0.005, p_{\mathrm{FDR}}=0.015\right)$, with the Healthy Control group's mean age $(14.20 \pm 1.76)$ being younger than those of the Depressed $(15.70 \pm$ $1.88)$ or Depressed + SB $(15.88 \pm 1.57)$ groups. However, prior work [58] found that $\mathrm{LICl}$ is inversely correlated with age in both healthy control and depressed youth; thus, it would be expected that a 


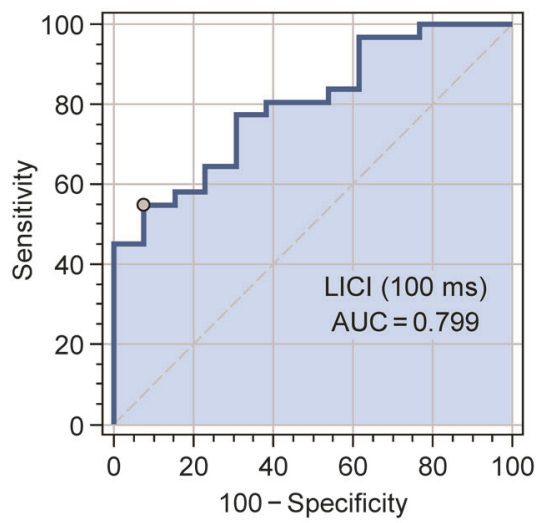

b

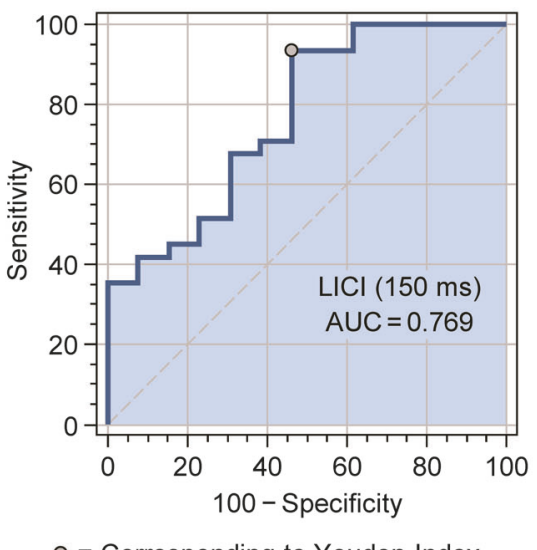

C

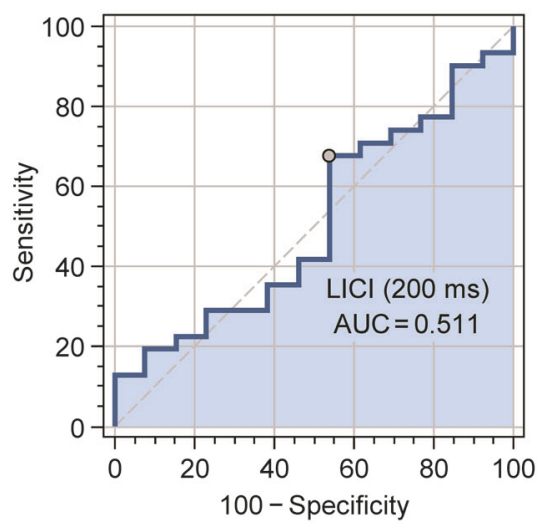

Fig. 4 Receiver operating characteristic (ROC) curves for discriminating Depressed vs. Depressed +SB youth in the a 100-ms, b 150-ms, and c 200-ms LICl paradigms.

healthy control group more closely matched in age to the depressed groups might show even greater inhibition of the conditioned MEP (and therefore greater differentiation from the Depressed and Depressed+SB groups). Participants in our study ranged from 12 to 20 years in age, complicating the assessment of depressive symptoms across such a broad span. While the CDRS-R has been utilized in numerous prior studies of depression and suicidality in adolescents (e.g., refs. [59-63]), it was designed originally for younger populations, and future studies that include young adults should include measures that are more developmentally appropriate to this age group. Furthermore, a large majority of the adolescents with histories of suicidal behavior in our sample were treated pharmacologically with selective serotonin reuptake inhibitors or serotonin-norepinephrine reuptake inhibitors, as were more than half of the depressed adolescents without suicidal behavior. While this is representative of many adolescents encountered in clinical practice (particularly those whose suicidal behavior has come to clinical attention), it does pose a potential confound, as antidepressant medications have been shown to potentiate some TMS measures of cortical inhibition such as CSP and $\mathrm{SICl}$ [64-66]. However, to our knowledge, the effect of antidepressant medications on $\mathrm{LICl}$ has not been examined. Although no participants in the current study reported use of benzodiazepines or other medications with direct GABAergic mechanisms, future investigators may wish to confirm the absence of confounding substances with urine or serum assays.

One major caveat in the interpretation of our results is the fact that the Depressed+SB group consisted of depressed adolescents with historical suicidal behavior; none had ongoing suicidal intent or preparatory behavior at the time of participation. This increases the possibility of recall bias as well as the likelihood of both type I and type II errors. While the inclusion of historically suicidal participants was necessary for pragmatic and ethical reasons, the present study did not assess whether disturbances in cortical excitability or inhibition are present in adolescents who are in the midst of acute suicidal crises. It is possible that acutely suicidal adolescents have similar patterns of impaired cortical inhibition or even more extreme $\mathrm{LICl}$ deficits; however, it is equally possible that acute suicidal crises have fundamentally different underlying neurobiology. Markers of disrupted excitatory-inhibitory balance have been shown to improve with time after suicide attempts [19], suggesting that neurobiological correlates of suicidality are at least partially dynamic. Studies that directly compare persons with active or very recent suicidal behavior with persons whose suicidal behavior is more distant, as well as prospective studies that repeat neurobiological assessments over time as suicidal risk changes, are necessary to answer this important "state-versus-trait" question, which has significant implications for the use of cortical inhibitory measures in assessing suicide risk. Additionally, all adolescents with histories of suicidal behavior included in our sample had diagnoses of unipolar depressive disorders. Much of the literature implicating GABA and glutamate in suicide is derived from unipolar depressed populations, although there are exceptions $[11,12,14,19,20]$. Despite our findings that indicate substantially greater cortical inhibitory impairment among adolescents with histories of suicidal behavior, caution should be exercised in generalizing this finding to adolescents with suicidal behavior in the context of other psychopathology. Further research is needed in additional adolescent populations with high rates of suicidal behavior (e.g., bipolar disorder, schizophrenia, obsessivecompulsive disorder, substance use disorders, and childhood adversity) to determine whether similar patterns of impaired cortical inhibition are present in suicidality across diagnostic groups. While the groups in our study were defined by a categorical diagnosis (depression) and the presence or absence of suicidal behavior history, the heterogeneity of depressive symptoms and diversity of suicidal histories are problematic when investigating the neurobiological correlates of such complex syndromes and behaviors. The use of transdiagnostic dimensional measures, as advocated by the National Institute of Mental Health's Research Domain Criteria initiative [67, 68], may yield more clinically relevant findings in suicide risk research than prior work on sociodemographic and diagnostic risk factors [69, 70]. Future studies should consider assessing dimensional constructs with particular relevance to both suicidal behavior and GABAergic neurotransmission, such as aggression and frustrative nonreward, anhedonia, fear and anxiety, impulsivity, and irritability, which may be important independent factors or may mediate suicidal behavior through interactions with neural risk factors, such as impaired cortical inhibition. Finally, the predictive utility of any single risk factor for suicidal behavior is likely to be limited, suggesting the need for combination or algorithmic approaches to risk assessment [6]. The accuracy and sensitivity of cortical inhibition in predicting a suicide-related outcome were improved by using two measures rather than one [55], and future investigations should explore combinations of promising biomarkers in order to optimize clinical usefulness.

To our knowledge, the current study represents the first examination of TMS-measured cortical excitability and inhibition in adolescents with suicidal behavior. The finding of impaired cortical inhibition, as indexed by $\mathrm{LICl}$, suggests that GABAergic 
neurotransmission has a role in the pathophysiology of suicidal behavior in this population, possibly distinct from the effect of the depressive illness. Cortical inhibition is a promising target for further research into risk assessment and interventions for suicidal behavior in adolescents.

\section{ACKNOWLEDGEMENTS}

This research was supported by grants from the Brain and Behavior Research Foundation (Young Investigator Award 20883), the Mayo Clinic Foundation (Departmental Small Grant Award), and the National Institute of Mental Health (K23 MH100266). The content is solely the responsibility of the authors and does not necessarily represent the official views of the National Institutes of Health.

\section{ADDITIONAL INFORMATION}

The online version of this article (https://doi.org/10.1038/s41386-018-0040-x) contains supplementary material, which is available to authorized users.

Competing interests: CPL receives research support from the Mayo Clinic Foundation Departmental Small Grant Program and is a site investigator for a multicenter study funded by Neuronetics, Inc. CJB receives research support from the Mayo Clinic Foundation Departmental Small Grant Program. JLVV receives equipment in-kind support from Assurex Health, Inc. for an investigator-initiated study and is a site investigator for a multicenter study funded by Neuronetics, Inc. GAW has received research support from Medtronic, Inc., Neuralynx, Inc., and Neuropace, Inc. ZJD has received research and equipment in-kind support for an investigatorinitiated study from Brainsway Ltd.; he also has served on the advisory board for $F$. Hoffmann-La Roche Ltd. and Merck \& Co., Inc. and has received speaker support from Eli Lilly and Co. PEC has received research grant support from Pfizer, Inc., NIMH (K23 MH100266), the Brain and Behavior Research Foundation, and the Mayo Clinic Foundation. He has served as a site subprincipal or principal investigator (without additional compensation) for Eli Lilly and Co., Forest Laboratories, Inc., Merck \& Co., Inc., and Pfizer, Inc.; has received equipment support from Neuronetics, Inc.; and receives supplies and genotyping services from Assurex Health, Inc. for an investigator-initiated study. He is a site primary investigator for a multicenter study funded by Neuronetics, Inc. The other authors declare no competing interests.

Publisher's note: Springer Nature remains neutral with regard to jurisdictional claims in published maps and institutional affiliations.

\section{REFERENCES}

1. Centers for Disease Control and Prevention, National Center for Injury Prevention and Control (2015). Web-based Injury Statistics Query and Reporting System (WISQARS) [online]. Accessed 23 Aug 2017. Available from: www.cdc.gov/injury/ wisqars.

2. World Health Organization. Preventing suicide: a global imperative. Geneva: WHO Press; 2014.

3. Kann L, McManus T, Harris WA, Shanklin SL, Flint KH, Hawkins J, et al. Youth risk behavior surveillance - United States, 2015. MMWR Surveill Summ. 2016;65:1-174.

4. Copeland WE, Goldston DB, Costello EJ. Adult associations of childhood suicidal thoughts and behaviors: a prospective, longitudinal analysis. J Am Acad Child Adolesc Psychiatry. 2017;56:958-65.

5. Olfson M, Blanco C, Wall M, Liu SM, Saha TD, Pickering RP, et al. National trends in suicide attempts among adults in the United States. JAMA Psychiatry. 2017;74:1095-103.

6. Franklin JC, Ribeiro JD, Fox KR, Bentley KH, Kleiman EM, Huang X, et al. Risk factors for suicidal thoughts and behaviors: a meta-analysis of 50 years of research. Psychol Bull. 2017;143:187-232.

7. Chang BP, Franklin JC, Ribeiro JD, Fox KR, Bentley KH, Kleiman EM, et al. Biological risk factors for suicidal behaviors: a meta-analysis. Transl Psychiatry. 2016;6:e887.

8. Oquendo MA, Sullivan GM, Sudol K, Baca-Garcia E, Stanley BH, Sublette ME, et al. Toward a biosignature for suicide. Am J Psychiatry. 2014;171:1259-77.

9. Sudol K, Mann JJ. Biomarkers of suicide attempt behavior: towards a biological model of risk. Curr Psychiatry Rep. 2017;19:31.

10. Sokolowski M, Ben-Efraim YJ, Wasserman J, Wasserman D. Glutamatergic GRIN2B and polyaminergic $O D C 1$ genes in suicide attempts: associations and geneenvironment interactions with childhood/adolescent physical assault. Mol Psychiatry. 2013;18:985-92.

11. Choudary PV, Molnar M, Evans SJ, Tomita H, Li JZ, Vawter MP, et al. Altered cortical glutamatergic and GABAergic signal transmission with glial involvement in depression. Proc Natl Acad Sci USA. 2005;102:15653-8.
12. Klempan TA, Sequeira A, Canetti L, Lalovic A, Ernst C, ffrench-Mullen J, et al. Altered expression of genes involved in ATP biosynthesis and GABAergic neurotransmission in the ventral prefrontal cortex of suicides with and without major depression. Mol Psychiatry. 2009;14:175-89.

13. Merali Z, Du L, Hrdina P, Palkovits M, Faludi G, Poulter MO, et al. Dysregulation in the suicide brain: mRNA expression of corticotropin-releasing hormone receptors and $\mathrm{GABA}_{\mathrm{A}}$ receptor subunits in frontal cortical brain region. J Neurosci. 2004;24:1478-85.

14. Sequeira A, Klempan T, Canetti L, Ffrench-Mullen J, Benkelfat C, Rouleau GA, et al. Patterns of gene expression in the limbic system of suicides with and without major depression. Mol Psychiatry. 2007;12:640-55.

15. Cheetham SC, Crompton MR, Katona CLE, Parker SJ, Horton RW. Brain GABA / $^{\prime}$ benzodiazepine binding sites and glutamic acid decarboxylase activity in depressed suicide victims. Brain Res. 1988;460:114-23.

16. Noga JT, Hyde TM, Herman MM, Spurney CF, Bigelow LB, Weinberger DR, et al. Glutamate receptors in the postmortem striatum of schizophrenic, suicide, and control brains. Synapse. 1997;27:168-76.

17. Bernstein HG, Tausch A, Wagner R, Steiner J, Seeleke $P$, Walter M, et al. Disruption of glutamate-glutamine-GABA cycle significantly impacts on suicidal behaviour: survey of the literature and own findings on glutamine synthetase. CNS Neurol Disord Drug Targets. 2013;12:900-13.

18. Poulter MO, Du L, Weaver ICG, Palkovits M, Faludi G, Merali Z, et al. GABA receptor promoter hypermethylation in suicide brain: implications for the involvement of epigenetic processes. Biol Psychiatry. 2008;64:645-52.

19. Erhardt S, Lim CK, Linderholm KR, Janelidze S, Lindqvist D, Samuelsson $M$, et al. Connecting inflammation with glutamate agonism in suicidality. Neuropsychopharmacology. 2013;38:743-52.

20. Lee R, Petty F, Coccaro EF. Cerebrospinal fluid GABA concentration: relationship with impulsivity and history of suicidal behavior, but not aggression, in human subjects. J Psychiatr Res. 2009;43:353-9.

21. Ziemann U, Reis J, Schwenkreis P, Rosanova M, Strafella A, Badawy R, et al. TMS and drugs revisited 2014. Clin Neurophysiol. 2015;126:1847-68.

22. Lefaucheur JP, Lucas B, Andraud F, Hogrel JY, Bellivier F, Del Cul A, et al. Interhemispheric asymmetry of motor corticospinal excitability in major depression studied by transcranial magnetic stimulation. J Psychiatr Res. 2008;42:389-98.

23. Levinson AJ, Fitzgerald PB, Favalli G, Blumberger DM, Daigle M, Daskalakis ZJ. Evidence of cortical inhibitory deficits in major depressive disorder. Biol Psychiatry. 2010;67:458-64.

24. Radhu N, de Jesus DR, Ravindran LN, Zanjani A, Fitzgerald PB, Daskalakis ZJ. A meta-analysis of cortical inhibition and excitability using transcranial magnetic stimulation in psychiatric disorders. Clin Neurophysiol. 2013;124:1309-20.

25. Croarkin PE, Nakonezny PA, Husain MM, Melton T, Buyukdura JS, Kennard BD, et al. Evidence for increased glutamatergic cortical facilitation in children and adolescents with major depressive disorder. JAMA Psychiatry. 2013;70: 291-9.

26. Kaufman J, Birmaher B, Brent D, Rao U, Flynn C, Moreci P, et al. Schedule for affective disorders and schizophrenia for school-age children-present and lifetime version (K-SADS-PL): initial reliability and validity data. J Am Acad Child Adolesc Psychiatry. 1997;36:980-8.

27. Poznanski EO, Grossman JA, Buchsbaum Y, Banegas M, Freeman L, Gibbons R. Preliminary studies of the reliability and validity of the Children's Depression Rating Scale. J Am Acad Child Psychiatry. 1984;23:191-7.

28. Posner K, Brown GK, Stanley B, Brent DA, Yershova KV, Oquendo MA, et al. The Columbia-Suicide Severity Rating Scale: initial validity and internal consistency findings from three multisite studies with adolescents and adults. Am J Psychiatry. 2011;168:1266-77.

29. Keel JC, Smith MJ, Wassermann EM. A safety screening questionnaire for transcranial magnetic stimulation. Clin Neurophysiol. 2001;112:720.

30. Daskalakis ZJ, Christensen BK, Chen R, Fitzgerald PB, Zipursky RB, Kapur S. Evidence for impaired cortical inhibition in schizophrenia using transcranial magnetic stimulation. Arch Gen Psychiatry. 2002;59:347-54.

31. Rossini PM, Burke D, Chen R, Cohen LG, Daskalakis Z, Di lorio R, et al. Non-invasive electrical and magnetic stimulation of the brain, spinal cord, roots and peripheral nerves: basic principles and procedures for routine clinical and research application. An updated report from an I.F.C.N. Committee. Clin Neurophysiol. 2015;126:1071-107.

32. Benjamini $\mathrm{Y}$, Hochberg Y. Controlling the false discovery rate: a practical and powerful approach to multiple testing. J R Stat Soc Ser B Methodol. 1995;57:289-300.

33. Chen R, Lozano AM, Ashby P. Mechanism of the silent period following transcranial magnetic stimulation: evidence from epidural recordings. Exp Brain Res. 1999;128:539-42.

34. Di Lazzaro V, Oliviero A, Mazzone P, Pilato F, Saturno E, Insola A, et al. Direct demonstration of long latency cortico-cortical inhibition in normal subjects and in a patient with vascular parkinsonism. Clin Neurophysiol. 2002;113:1673-9. 
35. Inghilleri M, Berardelli A, Cruccu G, Manfredi M. Silent period evoked by transcranial stimulation of the human cortex and cervicomedullary junction. J Physiol. 1993;466:521-34.

36. Nakamura $\mathrm{H}$, Kitagawa $\mathrm{H}$, Kawaguchi $\mathrm{Y}$, Tsuji $\mathrm{H}$. Intracortical facilitation and inhibition after transcranial magnetic stimulation in conscious humans. J Physiol. 1997:498:817-23.

37. Valls-Solé J, Pascual-Leone A, Wassermann EM, Hallett M. Human motor evoked responses to paired transcranial magnetic stimuli. Electroencephalogr Clin Neurophysiol. 1992;85:355-64.

38. Werhahn KJ, Kunesch E, Noachtar S, Benecke R, Classen J. Differential effects on motorcortical inhibition induced by blockade of GABA uptake in humans. J Physiol. 1999;517:591-7.

39. McDonnell $M N$, Orekhov $Y$, Ziemann $U$. The role of $G A B A_{B}$ receptors in intracortical inhibition in the human motor cortex. Exp Brain Res. 2006;173:86-93.

40. Pierantozzi M, Marciani MG, Palmieri MG, Brusa L, Galati S, Caramia MD, et al. Effect of vigabatrin on motor responses to transcranial magnetic stimulation: an effective tool to investigate in vivo GABAergic cortical inhibition in humans. Brain Res. 2004;1028:1-8.

41. Mohammadi B, Krampfl K, Petri S, Bogdanova D, Kossev A, Bufler J, et al. Selective and nonselective benzodiazepine agonists have different effects on motor cortex excitability. Muscle Nerve. 2006;33:778-84.

42. Teo JTH, Terranova C, Swayne OB, Greenwood RJ, Rothwell JC. Differing effects of intracortical circuits on plasticity. Exp Brain Res. 2009;193:555-63.

43. Cash RFH, Ziemann U, Murray K, Thickbroom GW. Late cortical disinhibition in human motor cortex: a triple-pulse transcranial magnetic stimulation study. J Neurophysiol. 2010;103:511-8.

44. Cash RFH, Ziemann U, Thickbroom GW. Inhibitory and disinhibitory effects on Iwave facilitation in motor cortex. J Neurophysiol. 2011;105:100-6.

45. Siebner HR, Dressnandt J, Auer C, Conrad B. Continuous intrathecal baclofen infusions induced a marked increase of the transcranially evoked silent period in a patient with generalized dystonia. Muscle Nerve. 1998;21:1209-12.

46. Benwell NM, Mastaglia FL, Thickbroom GW. Differential changes in long-interval intracortical inhibition and silent period duration during fatiguing hand exercise. Exp Brain Res. 2007;179:255-62.

47. Hammond G, Vallence AM. Modulation of long-interval intracortical inhibition and the silent period by voluntary contraction. Brain Res. 2007;1158:63-70.

48. Kimiskidis VK, Papagiannopoulos S, Kazis DA, Sotirakoglou K, Vasiliadis G, Zara F, et al. Lorazepam-induced effects on silent period and corticomotor excitability. Exp Brain Res. 2006;173:603-11.

49. Ben-Ari Y, Khazipov R, Leinekugel X, Caillard O, Gaiarsa JL. GABA $A_{A}$ NMDA and AMPA receptors: a developmentally regulated 'ménage à trois'. Trends Neurosci. 1997:20:523-9.

50. Rakhade SN, Jensen FE. Epileptogenesis in the immature brain: emerging mechanisms. Nat Rev Neurol. 2009:5:380-91.

51. Duncan CE, Webster MJ, Rothmond DA, Bahn S, Elashoff M, Shannon Weickert C. Prefrontal $G_{A B A}$ receptor a-subunit expression in normal postnatal human development and schizophrenia. J Psychiatr Res. 2010;44:673-81.

52. Silverstein FS, Jensen FE. Neonatal seizures. Ann Neurol. 2007;62:112-20.

53. Leinekugel X, Khalilov I, McLean H, Caillard O, Gaiarsa JL, Ben-Ari Y, et al. GABA is the principal fast-acting excitatory transmitter in the neonatal brain. In: DelgadoEscueta AV, Wilson WA, Olsen RW, Porter RJ, editors. Jasper's Basic Mechanisms of the Epilepsies, Third Edition: Advances in Neurology. Vol. 79. Philadelphia: Lippincott Williams \& Wilkins; 1999. p. 189-201.

54. Chugani DC, Muzik O, Juhász C, Janisse JJ, Ager J, Chugani HT. Postnatal maturation of human $\mathrm{GABA}_{\mathrm{A}}$ receptors measured with positron emission tomography. Ann Neurol. 2001;49:618-26.

55. Sun Y, Farzan F, Mulsant BH, Rajji TK, Fitzgerald PB, Barr MS, et al. Indicators for remission of suicidal ideation following magnetic seizure therapy in patients with treatment-resistant depression. JAMA Psychiatry. 2016;73:337-45.

56. de Jesus DR, Favalli GP, Hoppenbrouwers SS, Barr MS, Chen R, Fitzgerald PB, et al. Determining optimal rTMS parameters through changes in cortical inhibition. Clin Neurophysiol. 2014;125:755-62.
57. Daskalakis ZJ, Möller B, Christensen BK, Fitzgerald PB, Gunraj C, Chen R. The effects of repetitive transcranial magnetic stimulation on cortical inhibition in healthy human subjects. Exp Brain Res. 2006;174:403-12.

58. Croarkin PE, Nakonezny PA, Lewis CP, Zaccariello MJ, Huxsahl JE, Husain MM, et al. Developmental aspects of cortical excitability and inhibition in depressed and healthy youth: an exploratory study. Front Hum Neurosci. 2014;8:669.

59. Emslie GJ, Rush AJ, Weinberg WA, Kowatch RA, Hughes CW, Carmody T, et al. A double-blind, randomized, placebo-controlled trial of fluoxetine in children and adolescents with depression. Arch Gen Psychiatry. 1997;54:1031-7.

60. Emslie GJ, Heiligenstein JH, Wagner KD, Hoog SL, Ernest DE, Brown E, et al. Fluoxetine for acute treatment of depression in children and adolescents: a placebo-controlled, randomized clinical trial. J Am Acad Child Adolesc Psychiatry. 2002;41:1205-15.

61. Kennard B, Silva S, Vitiello B, Curry J, Kratochvil C, Simons A, et al. Remission and residual symptoms after short-term treatment in the Treatment of Adolescents with Depression Study (TADS). J Am Acad Child Adolesc Psychiatry. 2006;45:1404-11.

62. Brent D, Emslie G, Clarke G, Wagner KD, Asarnow JR, Keller M, et al. Switching to another SSRI or to venlafaxine with or without cognitive behavioral therapy for adolescents with SSRI-resistant depression: the TORDIA randomized controlled trial. JAMA. 2008;299:901-13.

63. Vitiello B, Brent DA, Greenhill LL, Emslie G, Wells K, Walkup JT, et al. Depressive symptoms and clinical status during the Treatment of Adolescent Suicide Attempters (TASA) Study. J Am Acad Child Adolesc Psychiatry. 2009;48:997-1004.

64. Manganotti P, Bortolomasi M, Zanette G, Pawelzik T, Giacopuzzi M, Fiaschi A Intravenous clomipramine decreases excitability of human motor cortex. A study with paired magnetic stimulation. J Neurol Sci. 2001;184:27-32.

65. Minelli A, Bortolomasi M, Scassellati C, Salvoro B, Avesani M, Manganotti P. Effects of intravenous antidepressant drugs on the excitability of human motor cortex: a study with paired magnetic stimulation on depressed patients. Brain Stimul. 2010;3:15-21.

66. Robol E, Fiaschi A, Manganotti P. Effects of citalopram on the excitability of the human motor cortex: a paired magnetic stimulation study. J Neurol Sci. 2004;221:41-46.

67. Garvey M, Avenevoli S, Anderson K. The National Institute of Mental Health Research Domain Criteria and clinical research in child and adolescent psychiatry. J Am Acad Child Adolesc Psychiatry. 2016;55:93-98.

68. Insel T, Cuthbert B, Garvey M, Heinssen R, Pine DS, Quinn K, et al. Research Domain Criteria (RDoC): toward a new classification framework for research on mental disorders. Am J Psychiatry. 2010;167:748-51.

69. Glenn CR, Cha CB, Kleiman EM, Nock MK. Understanding suicide risk within the Research Domain Criteria (RDoC) framework: insights, challenges, and future research considerations. Clin Psychol Sci. 2017a;5:568-92.

70. Glenn CR, Kleiman EM, Cha CB, Deming CA, Franklin JC, Nock MK. Understanding suicide risk within the Research Domain Criteria (RDoC) framework: a metaanalytic review. Depress Anxiety. 2017b;35:65-88.

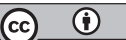

Open Access This article is licensed under a Creative Commons Attribution 4.0 International License, which permits use, sharing, adaptation, distribution and reproduction in any medium or format, as long as you give appropriate credit to the original author(s) and the source, provide a link to the Creative Commons license, and indicate if changes were made. The images or other third party material in this article are included in the article's Creative Commons license, unless indicated otherwise in a credit line to the material. If material is not included in the article's Creative Commons license and your intended use is not permitted by statutory regulation or exceeds the permitted use, you will need to obtain permission directly from the copyright holder. To view a copy of this license, visit http://creativecommons. org/licenses/by/4.0/.

(c) The Author(s) 2018 